\title{
Sustainable development aspects of biodiesel production and application in Brazil
}

\author{
O. Valente ${ }^{1}$, M. Silva ${ }^{2}$, R. Ávila ${ }^{3}$, J. Vianna $^{4} \&$ J. Sodré ${ }^{2}$ \\ ${ }^{I}$ Federal Center of Technological Education of Minas Gerais, Brazil \\ ${ }^{2}$ Pontifical Catholic University of Minas Gerais, Brazil \\ ${ }^{3}$ FIAT Automobiles S.A., Brazil \\ ${ }^{4}$ University of Brasilia, Brazil
}

\begin{abstract}
Concerns about climate change effects have prompted many countries to search for solutions to reduce fossil fuel consumption. In the last few years biodiesel production has gained world attention, as it is seen as a sustainable and renewable energy source. Biodiesel is a natural substitute for diesel oil, and can be obtained from different oleaginous plants. However, there are worries about devastation of forests and biodiversity-rich areas to produce biodiesel. Even considering biodiesel as a promising solution, the impacts of its production must be carefully evaluated. This work examines the Brazilian scenario for biodiesel production and use as an automotive fuel. Native and adapted oleaginous in many Brazilian regions and their potentiality for biodiesel production are presented. Experimental results of hydrocarbons $(\mathrm{HC})$, carbon monoxide $(\mathrm{CO})$, and carbon dioxide $\left(\mathrm{CO}_{2}\right)$ emissions from a diesel power generator fuelled by blends of diesel oil and castor oil or soybean biodiesel are also presented.
\end{abstract}

Keywords: biodiesel, renewable energy, sustainable development, emissions.

\section{Introduction}

In Brazil, load and public transportation is mainly based on vehicles equipped with diesel-cycle engines. More than 2 million trucks travel along 1.6 million kilometers of roads, delivering $61 \%$ of the total goods cargo. In urban areas 95 thousand buses make the basis for the public transportation system. The transportation system is responsible for an annual consumption of 42.1 billion liters of diesel, from which only 38.6 billion are refined in Brazil. Another 6.4 
billion liters of diesel oil comes from imported low-viscosity crude oil, and about 3.5 billion liters of diesel oil are acquired in the international market. Discussions about the introduction of biodiesel fuel as a Brazilian alternative energy source is based upon arguments that range from diesel oil imports reduction to social inclusion, and environmental issues.

Brazil is located between the parallels $5^{\circ} 16^{\prime} 19^{\prime \prime}$ north latitude and $33^{\circ} 45^{\prime} 09^{\prime \prime}$

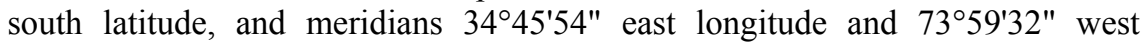
longitude. The territory is simultaneously crossed by the Equator line in the north and the Tropic of Capricorn in the south. About $1 \%$ of the Brazilian land is located in the Northern Hemisphere, and $92 \%$ is located in the Southern Hemisphere. They altogether make part of the Tropical Zone, with the $7 \%$ left belonging to the Mild Zone. Its localization compromises two big climate regions, one of those is controlled by equatorial and tropical air masses and the other one is controlled by tropical and polar air masses. Its diversity in climate and multiple conditions of soil allows for a variety of vegetation along the Brazilian territory.

A study performed by the Minas Gerais Technological Center Foundation (CETEC-MG) [1], published in 1983, pointed to nine oleaginous plants as economically efficient sources for biodiesel production. The mentioned study has not included peanuts, cotton, canola (colza), and soybeans, which have recently been widely used as raw material for biofuels production. It may be taken into consideration that each oleaginous shall produce oil with different biochemical characteristics. Some characteristics, such as viscosity and density, are parameters that influence engine fuel consumption and exhaust emissions. Use of biodiesel fuel as a renewable energy source could shortly become economically feasible and ecologically correct, as shown by the Brazilian ethanol experience.

\section{Brazilian potential for biodiesel production}

With a diversified climate, regular rains, abundant solar energy and almost $13 \%$ of all drinking water available on the planet, according to data supplied by the Brazilian Ministry of Agriculture, Brazil has 388 million hectares of fertile and high productivity soil. From this territory, about 90 million hectares have not yet been explored. Besides, Brazil is one of the few countries in the world where it is possible to plant in mild and tropical areas. Blessed by nature itself, Brazilian agriculture can supply up to two harvests of grains yearly.

According to the Brazilian Ministry of Agriculture, from 1990 to 2003 grain production in Brazil increased 131\%. During this period, the cultivated area increased only $16.1 \%$. Thirteen different harvests were mainly responsible for this growth. The efficiency of agricultural practices rose from 1.5 to 2.8 tons per hectare. Research on farming and cattle-raising has been responsible for the development of 529 newly adapted crops to each climate and soil in the main productions region in Brazil. It has also counted on the use of better technology with less impact on the environment. Many "green" procedures have been adopted, such as straw plantation, tests to apply only the necessary nutrients, recovery of land degradation caused by harvesting of crops and overgrazing. 
With at least 90 million hectares of fertile lands available, Brazil can increase its current grains production at least three times, from 123.2 million to 367.2 million tons. This amount can even increase if it is taken into consideration that $30 \%$ out of 220 million hectares used nowadays with pastures can become fields of crops due to the boom in cattle farming. The country is likely to reach 140 million hectares addressed to agriculture since the expansion of its cultivated borders in the center-west and north-east regions. This is calculated without causing any damage to the Brazilian rain forest, being in accordance and totally harmonic with environmental policy. Brazilian past experience shows it to be possible to produce biofuels without interfering with food production. As an example, producing ethanol fuel from sugar-cane was a natural choice, since distillation of its biomass is an activity performed in the country since the $16^{\text {th }}$ century.

Oils for biofuel production can be taken from vegetables or animals. Within the strategic plan of the Brazilian Agro-Cattle Research Company (EMBRAPA), there are some potential plants for biodiesel production, such as: tucumã (Astrocaryum aculeatum), macaúba (Acrocomia intumescens), pequi (Caryocar brasiliense), physic nut (Jatropha curcas), baru (Hibiscus tiliaceus), murumuru (Astrocaryum murumuru), buriti (Trithrinax schizophylla), inajá (Maximiliana maripa), andiroba (Carapa guianensis), tucum (Astrocaryum vulgare), babaçu (Orbignya phalerata), tungue (Aleurites moluccana), colza Brassica napus), turnip (Brassica rapa), crambe, sesamum, palm (Elaeis guineensis), indaiá (Attalea oleifera), castor oil plant (Ricinus communis) and flax (Linum usitatissimum). These vegetables, native and well-adapted to several microclimates in Brazil, can produce more than 1 ton per hectare. Table 1 shows some of those oleaginous, their oil productivity per hectare and the region in which they grow best.

Table 1: Brazilian oleaginous plants location and estimated oil production.

\begin{tabular}{||l|c|c||}
\hline \hline PLANTS & Location & Production (TON/HA) \\
\hline Palm tree & Amazonas, Pará & 4.37 \\
\hline Macaúba & Minas Gerais, Goiás & 2.63 \\
\hline Physic nut & Bahia, Minas Gerais & 3.99 \\
\hline Indaiá & Bahia, Minas Gerais & 0.94 \\
\hline Castor oil & Northeastern region & 0.73 \\
\hline Sunflower & Southern region, Mato Grosso, Goiás & 0.31 \\
\hline Soybean & Southern region, Mato Grosso, Goiás & 0.3 \\
\hline
\end{tabular}

Source: CETEC/MG

\section{Literature review on engine use of biodiesel}

McCormic et al [2] studied the effects of fourteen oils from different origins on emissions from heavy-duty vehicles. The authors verified that the biodiesel molecular structure has a substantial impact on exhaust emissions. Particulate 
matter and oxides of nitrogen emissions increased with increasing fuel density. The cetane number did not influence particulate matter emissions (PM), but a higher cetane number decreased oxides of nitrogen emissions $\left(\mathrm{NO}_{\mathrm{X}}\right)$.

Haas et al [3] demonstrated that the use of vegetables or animal fat oils, modified by the transesterification process, reduces engine carbon and particulate matter emissions, while increasing oxides of nitrogen emissions.

Çetinkaya and Karaosmanoğlu [4] obtained results from a diesel power generator that demonstrate soot reduction by use of a blend of $20 \%$ used frying oil biodiesel in diesel oil. Use of biodiesel increased the specific fuel consumption in comparison with operation with petroleum-based diesel oil only.

Szybist et al [5] concluded that retarding injection timing improves engine performance when biodiesel is used as fuel.

Tsolakis [6] demonstrated that utilization of exhaust gas recirculation (EGR) reduces particulate matter and oxides of nitrogen emissions.

Leung et al [7] carried out experiments in a single-cylinder engine with modified injection timing, orifice diameter and injection pressure. The objective was to verify the influence of those parameters on $\mathrm{HC}, \mathrm{NO}_{\mathrm{X}}$, and $\mathrm{PM}$ emissions. The authors noticed that increasing orifice diameter, retarding the injection timing by four crank angle degrees, and increasing the injection pressure approximated the fuel burning process to top dead center, thus increasing combustion efficiency. It was concluded that, with adequate settings, fuelling the engine with pure biodiesel could decrease hydrocarbons, oxides of nitrogen and particulate matter emissions with respect to diesel oil.

Kegl [8] performed experiments in a heavy-duty diesel engine to adequate it for colza biodiesel fuelling. The author attempted to optimize the injection setting for minimum exhaust emissions and fuel consumption. Pure biodiesel and a blend of $2 \%$ of biodiesel in diesel oil were tested. The results showed that fuelling the unmodified engine purely with biodiesel caused a decrease in performance. Modifications in the injection system setting significantly reduced hydrocarbons, oxides of nitrogen and soot emissions. A slight reduction of carbon monoxide emission was also observed when pure biodiesel was used, while engine output power ant exhaust gas temperature was unaltered. The engine thermal efficiency was slightly increased with use of pure biodiesel, but specific fuel consumption was also increased by about $10 \%$.

\section{Experiments in a biodiesel-fuelled engine}

Blends of petroleum-based diesel oil and two types of biodiesel, obtained from castor oil and soybean, were tested in laboratory. A four-cylinder, 3.8-liter, compression-ignition engine connected to a power generator of $50 \mathrm{~kW}$ maximum power was used to measure $\mathrm{HC}, \mathrm{CO}$, and $\mathrm{CO}_{2}$ exhaust emissions. A bank of electric resistances was used to apply load to the power generator, allowing for minimum load steps of $2.5 \mathrm{~kW}$. A power quality analyzer was used to record the electric current frequency, intensity and tension. A flame ionization detector analyzer (FID) was used to measure total exhaust hydrocarbons concentration 
Table 2: $\quad$ Description of fuel blends used in the tests.

\begin{tabular}{||l|l||}
\hline \hline SYMBOL & \multicolumn{1}{|c|}{ COMPOSITION } \\
\hline B0 & Petroleum-based diesel oil \\
\hline B5M & Blend of 5\% castor oil biodiesel and 95\% diesel oil \\
\hline B5S & Blend of 5\% soybean biodiesel and 95\% diesel oil \\
\hline B20M & Blend of 20\% castor oil biodiesel and 80\% diesel oil \\
\hline B20S & Blend of 20\% soybean biodiesel and 80\% diesel oil \\
\hline B35M & Blend of 35\% castor oil biodiesel and 65\% diesel oil \\
\hline B35S & Blend of 35\% soybean biodiesel and 65\% diesel oil \\
\hline B50S & Blend of 50\% soybean biodiesel and 50\% diesel oil \\
\hline B85S & Blend of $85 \%$ soybean biodiesel and $15 \%$ diesel oil \\
\hline \hline
\end{tabular}

(HC). Carbon monoxide $(\mathrm{CO})$ and carbon dioxide $\left(\mathrm{CO}_{2}\right)$ were both measured by a non-dispersive infrared analyzer (NDIR). Ambient conditions were monitored through a thermal-hygrometer and a barometer.

The measurements aimed at expressing the results in terms of exhaust gas concentration versus the electric power generated. The engine had a warm-up period of about $15 \mathrm{~min}$ and the gas analyzers were turned on about one hour prior to the tests. After each load setting a 2 min interval was allowed for stabilization of the engine before proceeding with the instrument readings. The gas sample into the analyzers was collected direct from the engine exhaust, close to the exhaust port. Ambient air temperature was kept at $28 \pm 2{ }^{\circ} \mathrm{C}$. The exhaust components were measured at the nominal loads of $0,10,20,30$, and 40kW. All the tests were performed in the Engines, Fuels and Power Generation Laboratory of the Pontifical Catholic University of Minas Gerais (PUC Minas).

\section{Results and discussion}

Figures 1 to 6 show the variation of exhaust $\mathrm{HC}, \mathrm{CO}$ and $\mathrm{CO}_{2}$ emissions for varying biodiesel concentration and engine load. The fuel blends tested are those described in Table 2. The results shown represent the average of three tests performed for each fuel.

The presence of exhaust hydrocarbons is a result of incomplete combustion occurring in the chamber (Figs. 1 and 2). Hydrocarbons concentration is higher for very high or very low load. Under very low loads, the lean air/fuel mixture causes slow combustion reaction and, eventually, flame extinction. With very high loads, the enriched air/fuel mixture can provoke flame quenching due to temperature drop in the chamber caused by excessive fuel evaporation.

In Figs. 1 and 2, the increase of $\mathrm{HC}$ emissions with the use of the biodiesel fuel blends is accounted to the biodiesel physical-chemical characteristics. Both castor oil and soybean biodiesel have higher density than diesel oil (Fig. 3). As 
the fuel injection system displaces constant volumes, the same volumetric amount injected corresponds to higher biodiesel mass amount with respect to diesel oil, enriching the air/fuel mixture (Figs. 4 and 5). As mentioned before, the engine injection system was kept with its original settings, which is optimized for diesel oil operation. This result indicates the need of modifications in the injection system to optimize it for biodiesel operation, as observed by Szybist et al [5], Leung et al [7], and Kegl [8]. The effects of fuel density are more clearly noticed for castor oil biodiesel blends (Fig. 1).

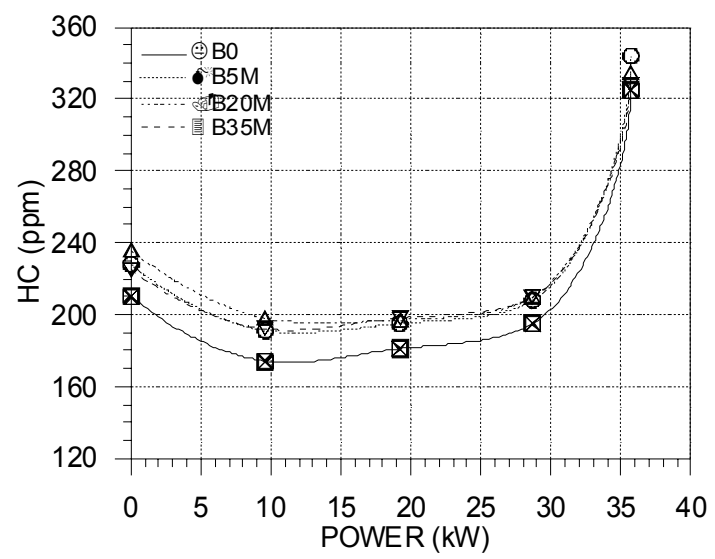

Figure 1: Variation of exhaust hydrocarbons concentration with engine load for castor oil biodiesel blends.

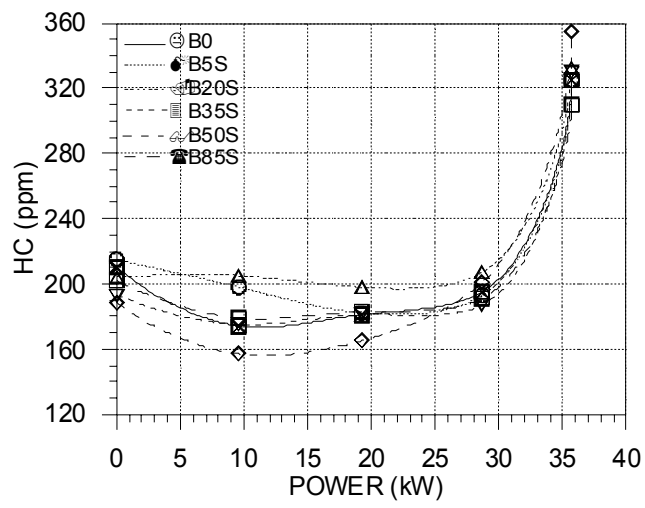

Figure 2: Variation of exhaust hydrocarbons concentration with engine load for soybean biodiesel blends. 


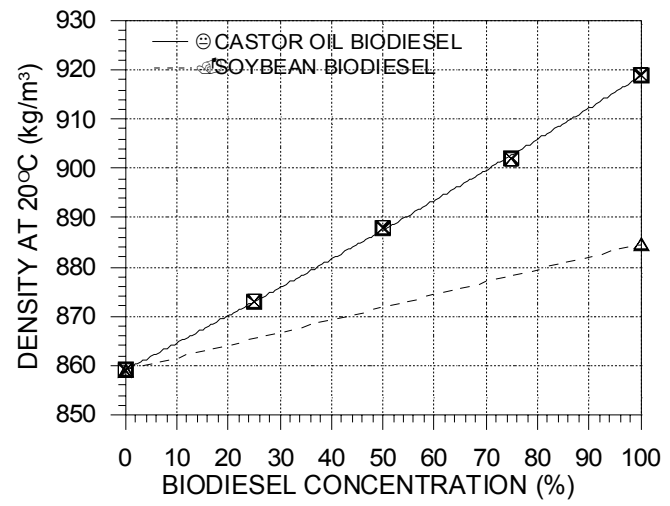

Figure 3: Variation of fuel density with biodiesel concentration.

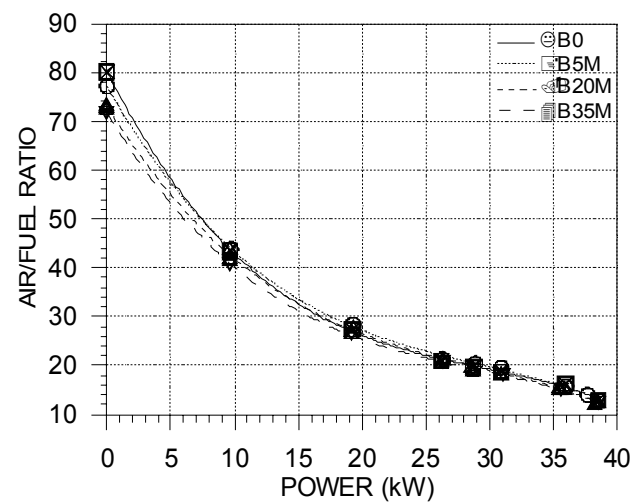

Figure 4: Variation of mixture strength with engine load for castor oil biodiesel blends.

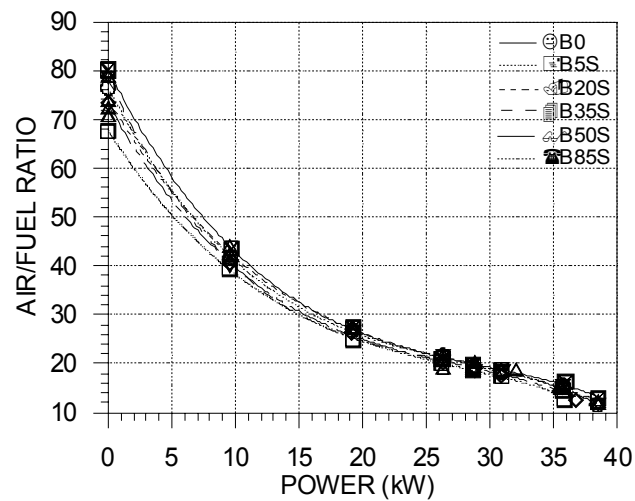

Figure 5: Variation of mixture strength with engine load for soybean biodiesel blends. 
Figures 6 and 7 show a linear decrease on carbon monoxide concentration with increasing load. That is an indication of better fuel atomization being attained under higher load, probably caused by the higher combustion chamber temperatures that follow higher peak pressures. Increased biodiesel concentration in the fuel blend provokes an increase in $\mathrm{CO}$ emissions. That is because of air/fuel mixture enrichment (see Figs. 4 and 5) due to higher biodiesel mass being injected by the fuel pump, which volume displacement is optimized to diesel oil operation. As previously mentioned, once biodiesel density is higher than diesel oil density (see. Fig. 3), for a same displaced volume a higher biodiesel mass is injected in comparison to diesel oil. For a given load and biodiesel concentration, soybean biodiesel showed higher $\mathrm{CO}$ concentration than castor oil biodiesel (Figs. 6 and 7).

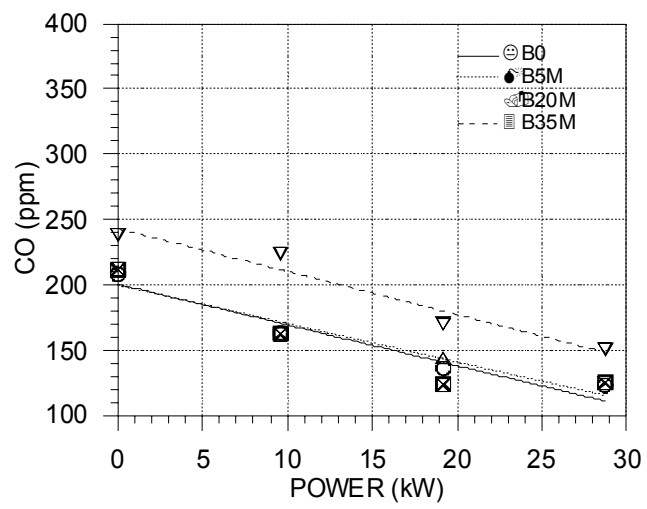

Figure 6: Variation of exhaust carbon monoxide concentration with engine load for castor oil biodiesel blends.

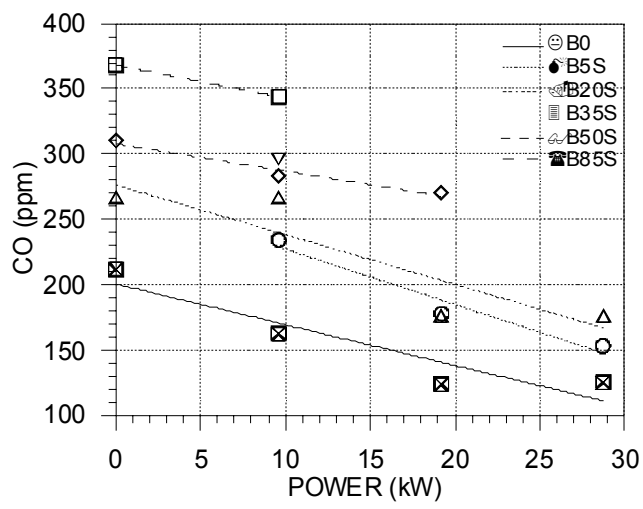

Figure 7: Variation of exhaust carbon monoxide concentration with engine load for soybean biodiesel blends. 
In Figs. 8 and 9, an increase in $\mathrm{CO}_{2}$ emissions with increasing load is observed. Carbon dioxide formation increases as the air/fuel mixture strength becomes closer to stoichiometric (see Figs. 4 and 5). For a given load applied to the engine, $\mathrm{CO}_{2}$ concentration is basically the same for any biodiesel concentration in the fuel blend. The concentration of $\mathrm{CO}_{2}$ also showed to be insensitive to biodiesel type, showing practically the same results for both, castor oil and soybean biodiesel.

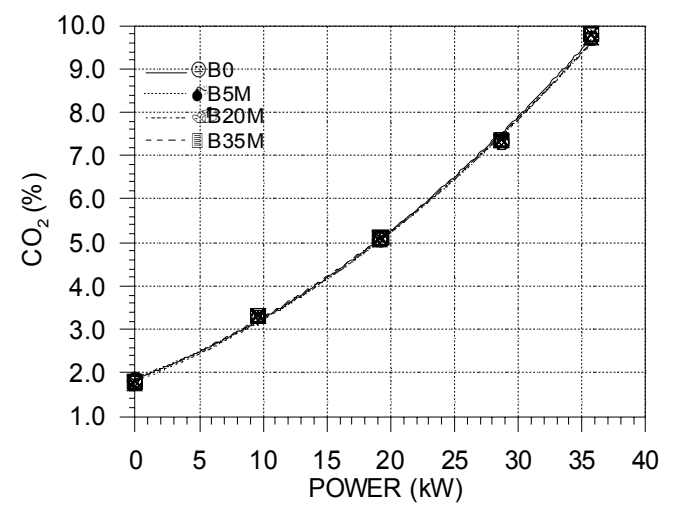

Figure 8: Variation of exhaust carbon dioxide concentration with engine load for castor oil biodiesel blends.

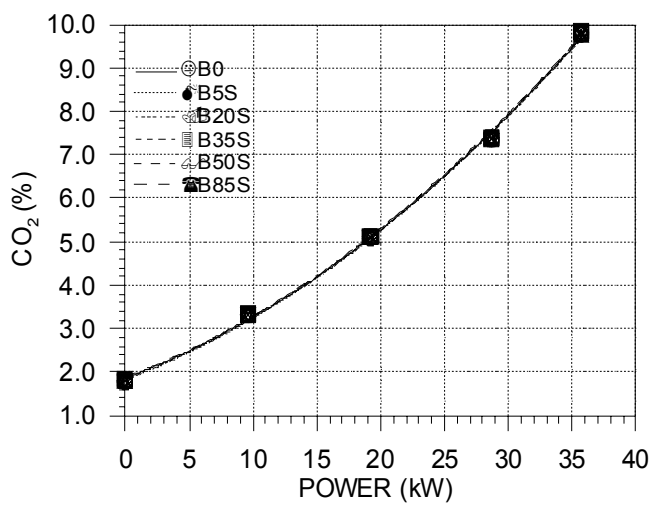

Figure 9: Variation of exhaust carbon dioxide concentration with engine load for soybean biodiesel blends.

\section{Conclusions}

- Brazil presents a territory appropriate climate and soil for oleaginous seeds production, but faces the task to choose from more than ten oleaginous types available for biodiesel production the most economically feasible. 
- Experiments in a power generator showed that exhaust hydrocarbons concentration increase with increasing castor oil or soybean biodiesel concentration in diesel oil, with no modifications made in the engine.

- An increase in castor oil or soybean biodiesel concentration in diesel oil increases exhaust $\mathrm{CO}$ emission, the first showing lower carbon monoxide emissions levels than the second for loads and concentrations.

- Carbon dioxide emissions level was not altered by biodiesel type or concentration in diesel oil throughout the load range studied

- Due to increasing fuel density, air/fuel mixture is enriched with increasing biodiesel concentration for all loads

- Use of biodiesel requires modification in power generator injection systems to reduce engine exhaust pollutant emissions and $\mathrm{CO}_{2}$.

\section{Acknowledgements}

The authors thank CNPq, for the financial support to this project, and Varginha City Council, for the supply of biodiesel.

\section{References}

[1] Minas Gerais Technological Center Foundation (CETEC-MG). Production of liquid fuels from vegetable oils, Belo Horizonte, Brazil, 1983.

[2] McCormick, R.L., Graboski, M.S., Alleman, T.L. \& Herring, A.M., Impact of biodiesel source material and chemical structure on emissions of criteria pollutants from a heavy-duty engine. Environmental Science and Technology, 35(9), pp. 1742-1747, 2001.

[3] Haas, M.J., Scott, K.M., Alleman, T.L. \& McCormick, R.L., Biodiesel fuel prepared from soybean soapstock: a high quality renewable fuel produced from a waste feedstock. Energy \& Fuels, 15(5), pp. 1207-1212, 2001.

[4] Çetinkaya, M. \& Karaosmanoğlu, F., A new application area for used cooking oil originated biodiesel: generators. Energy \& Fuels, 19(2), pp. 645-652, 2005.

[5] Szybist, J.P., Boehmana, A.L., Taylorb, J.D. \& McCormick, R.L., Evaluation of formulation strategies to eliminate the biodiesel $\mathrm{NO}_{\mathrm{X}}$ effect. Fuel Processing Technology, 86, pp. 1109-1126, 2005.

[6] Tsolakis, A., Effects on particle size distribution from the diesel engine operating on RME-biodiesel with EGR. Energy \& Fuel, 20(4), pp. 1418$1424,2006$.

[7] Leung, D., Lou, Y. \& Chan, T.L., Optimization of exhaust emissions of a diesel engine fuelled with biodiesel. Energy \& Fuels, 20(3), 1015-1023, 2006.

[8] Kegl, B., Experimental investigation of optimal timing of the diesel engine injection pump using biodiesel. Energy \& Fuels, 20(4), pp. 1460-1470, 2006. 